\title{
Predictors of suicidal thoughts and behavior in children: results from penalized logistic regression analyses in the $A B C D$ study
}

Laura S. van Velzen ${ }^{* 1,2}$, Yara J. Toenders ${ }^{* 1,2}$, Aina Avila-Parcet ${ }^{3}$, Richard Dinga ${ }^{4}$, Jill A. Rabinowitz $^{5}$, Adrián I. Campos ${ }^{6,7}$, Neda Jahanshad ${ }^{8}$, Miguel E. Rentería ${ }^{6,7}$, Lianne Schmaal ${ }^{1,2}$

${ }^{*}$ Authors share first authorship

${ }^{1}$ Orygen, Parkville, VIC, Australia

${ }^{2}$ Centre for Youth Mental Health, University of Melbourne, Melbourne, VIC, Australia

${ }^{3}$ Department of Psychiatry, Hospital de la Santa Creu i Sant Pau, Barcelona, Spain

${ }^{4}$ Donders Institute for Brain, Cognition and Behaviour, Radboud University, Nijmegen, the

Netherlands

${ }^{5}$ Department of Mental Health, Bloomberg School of Public Health, Johns Hopkins University, Baltimore, Maryland, USA

${ }^{6}$ Department of Genetics \& Computational Biology, QIMR Berghofer Medical Research Institute, Brisbane, QLD, Australia

${ }^{7}$ School of Biomedical Sciences, Faculty of Medicine, The University of Queensland, Brisbane, Queensland, Australia

${ }^{8}$ Imaging Genetics Center, Mark \& Mary Stevens Neuroimaging \& Informatics Institute, Keck School of Medicine, University of Southern California, Los Angeles, CA, USA

Running title: Predicting suicidal thoughts and behavior in children

Number of words abstract: 247

Number of words main text: 3908

Number of tables: 7

Number of figures: 2

Key words: suicide, youth, machine learning, children, penalized logistic regression 
medRxiv preprint doi: https://doi.org/10.1101/2021.02.15.21251736; this version posted February 19, 2021. The copyright holder for this preprint (which was not certified by peer review) is the author/funder, who has granted medRxiv a license to display the preprint in perpetuity. All rights reserved. No reuse allowed without permission.

\section{Corresponding author:}

$\begin{array}{ll}\text { Name: } & \text { Laura S. van Velzen } \\ \text { Affiliation: } & \text { Orygen }\end{array}$

Centre for Youth Mental Health, University of Melbourne

Address: $\quad 35$ Poplar Road, Parkville, VIC 3052, Australia

Telephone: $\quad+31620528057$

Email:

laura.vanvelzen@unimelb.edu.au 
medRxiv preprint doi: https://doi.org/10.1101/2021.02.15.21251736; this version posted February 19, 2021. The copyright holder for this preprint

(which was not certified by peer review) is the author/funder, who has granted medRxiv a license to display the preprint in perpetuity.

All rights reserved. No reuse allowed without permission.

\begin{abstract}
Despite numerous efforts to predict suicide risk in children, the ability to reliably identify youth that will engage in suicide thoughts or behaviors (STB) has remained remarkably unsuccessful. To further knowledge in this area, we apply a novel machine learning approach and examine whether children with STB could be differentiated from children without STB based on a combination of sociodemographic, physical health, social environmental, clinical psychiatric, cognitive, biological and genetic characteristics. The study sample included 5,885 unrelated children (50\% female, $67 \%$ white) between 9 and 11 years old from the Adolescent Brain Cognitive Development (ABCD) study. Both parents and youth reported on children's STB and based on these reports, we divided children into three subgroups: 1. children with current or past STB, 2. children with psychiatric disorder but no STB (clinical controls) and 3. healthy control children. We performed binomial penalized logistic regression analysis to distinguish between groups. The analyses were performed separately for child-reported STB and parentreported STB. Results showed that we were able to distinguish the STB group from healthy controls and clinical controls (area under the receiver operating characteristics curve (AUROC) range: $0.79-0.81$ and $0.70-0.78$ respectively). However, we could not distinguish children with suicidal ideation from those who attempted suicide (AUROC range 0.49-0.59). Factors that differentiated the STB group from the clinical control group included family conflict, prodromal psychosis symptoms, impulsivity, depression severity and a history of mental health treatment. Future research is needed to determine if these variables prospectively predict subsequent suicidal behavior.
\end{abstract}


medRxiv preprint doi: https://doi.org/10.1101/2021.02.15.21251736; this version posted February 19, 2021. The copyright holder for this preprint

(which was not certified by peer review) is the author/funder, who has granted medRxiv a license to display the preprint in perpetuity.

All rights reserved. No reuse allowed without permission.

\section{Introduction}

Despite national and international prevention efforts aimed at reducing suicide risk, the rate of suicide still continues to rise globally [1]. Suicidal thoughts and behaviors typically emerge during adolescence, and their incidence rates rise sharply from childhood to adolescence [2]. Suicide is the second leading cause of death for young people between 10 and 24 years of age $[3,4]$. To better target prevention and intervention efforts, we must increase our understanding of risk factors for suicidal thoughts and behaviors in children and adolescents.

To our knowledge, only two studies have investigated risk factors associated with suicidal thoughts and behaviors in a very large sample of children between the ages of 9 and 11 $(\mathrm{N}=11,875)$ in the Adolescent Brain Cognitive Development Study [5-7]. DeVille et al. [6] examined social-environmental factors using generalized linear mixed-effects models and revealed that higher levels of family conflict was associated with suicidal ideation, while low parental monitoring was associated with both ideation and attempt. Janiri et al. [5] examined a broader range of potential risk and protective factors for suicidality using logistic regression and also showed that higher levels of family conflict was a risk factor for suicidality, the presence of child psychopathology and longer weekend screen time were also found to be risk factors, while greater parental supervision and positive school involvement were protective factors. However, these studies have not included biological measures (e.g. genetics or regional brain activity), which have been shown to play a role in suicidal thoughts and behavior in adolescents [8]. In addition, these studies have not examined whether a combination of factors, instead of examining associations per risk factor, distinguishes children with and without suicidal thoughts or behavior.

To address these gaps, we examine whether a combination of a broad range of factors (sociodemographic, physical health, clinical psychiatric, cognitive, social environmental, genetic, 
medRxiv preprint doi: https://doi.org/10.1101/2021.02.15.21251736; this version posted February 19, 2021. The copyright holder for this preprint

(which was not certified by peer review) is the author/funder, who has granted medRxiv a license to display the preprint in perpetuity.

All rights reserved. No reuse allowed without permission.

and biological factors) in a sample of almost 6,000 unrelated children in the ABCD study could differentiate children with a lifetime history of suicidal thoughts and/or suicide attempt and two control groups. Since a large number of children in the suicidal thoughts and behavior (STB) group also have a psychiatric disorder, the control groups were: 1) children without psychiatric disorder (healthy controls; HC), 2) children with psychiatric disorder but no history of suicidal thoughts or behavior (clinical controls; CC). To this end, we used binomial penalized logistic regression and a feature selection approach, which can determine which type of predictors contribute most to the classification of STB.

In addition to examining risk for suicidal thoughts and behaviors, it is important to identify clinical, biological, and cognitive factors that distinguish between individuals who only think about suicide (suicidal ideation), and those who attempt suicide [e.g. 9, 10]. This is relevant as it has been shown that only one third of individuals with suicidal thoughts actually attempt suicide [11]. Thus, identifying factors that differentiate these individuals may identify young people at high risk for suicidal behavior and may further inform targeted prevention and intervention efforts. As a final aim, we examined which factors differentiated children with (a history of) suicidal ideation, but no history of suicidal behavior, and those that have attempted suicide during their lives.

\section{Methods}

\section{Participants}

All data included in this study were collected as part of the Adolescent Brain Cognitive Development (ABCD) study (Annual Release 2.1;https://nda.nih.gov/abcd). Data were drawn from the baseline measurement of the ABCD study, which included data from 11,875 children between the ages of 9 and 11 assessed at 22 sites across the United States. The recruitment method and inclusion and exclusion criteria of the ABCD study are described elsewhere [7]. All 
adolescents provided assent and their parents provided consent. The Institutional Review Board of the University of California at San Diego approved the study protocol and data collection and is responsible for ethical oversight.

In the current study, we only included unrelated children, leading to a sample size of 9,985 children (see Supplemental Note 1 and Supplemental Figure S1). In addition, 9 children were excluded due to missing sociodemographic data, and 4000 children were excluded due to missing neuroimaging data or excluded due to low quality of neuroimaging data (as suggested by the $A B C D$ team). This resulted in a total sample size of 5885 children for the current analysis.

\section{Definition of outcome groups}

Suicidal thoughts and behaviors (interrupted, aborted or actual suicide attempt) and psychiatric diagnoses were assessed using the child-and parent-reported of the computerized Kiddie Schedule for Affective Disorders and Schizophrenia for DSM-5 (KSADS-5) [12]. As previous findings showed low correspondence between parent- and child-reported STBs in the ABCD sample [5], we created two STB outcome variables, one for each reported (see Supplemental Note 2 for more details on group definitions). Children with comorbid psychiatric disorders were not excluded from the STB group. The definitions for the $\mathrm{HC}$ and $\mathrm{CC}$ group were the same across parent and child outcome variables, however, due to differences in the STB outcome, the sample of the $\mathrm{HC}$ and $\mathrm{CC}$ groups also differed.

For the parent-reported STB outcome variable, we created three groups based on the K-SADS5 diagnostic information: 1) healthy control group (no parent-reported or child-reported psychiatric diagnosis was present and no parent-reported lifetime history of suicidal thoughts and behavior; $\mathrm{N}=2,415$;) 2) clinical control group (a parent-reported or child-reported psychiatric 
diagnosis was present, but there was no lifetime parent-reported history of suicidal thoughts or behavior; $\mathrm{N}=2,976$ ); 3) STB group (lifetime parent-reported suicidal thoughts or behavior was reported; $\mathrm{N}=494)$.

The child-reported STB outcome variable included the following three groups: 1) healthy control group (no parent-reported or child-reported psychiatric diagnosis was present and no childreported lifetime history of suicidal thoughts or behavior; $N=2,367$ ); 2) clinical control group (a parent-reported or child-reported psychiatric diagnosis was present, but there was no lifetime child-reported history of suicidal thoughts or behavior; $\mathrm{N}=2,985$ ); 3) STB group (lifetime childreported suicidal thoughts or behavior was reported; $\mathrm{N}=528$ ).

In addition, ancillary analyses were performed on the individuals that were in the same group according to both the parent and child outcome variables (see Supplemental Note 3).

For secondary analyses, we created two additional outcome variables to distinguish children with lifetime suicidal thoughts (ideation) from children with a history of suicidal behavior (attempt). The child-reported outcome variable included 461 children with self-reported suicidal ideation but no history of attempt and 67 children with a self-reported history of suicide attempt. The parent-reported suicide ideation and suicide attempt outcome variables included 464 children with suicidal ideation but no history of attempt, and 30 children with a history of suicide attempt (see Supplemental Note 4 for more details on group definitions).

\section{$\underline{\text { Risk factors }}$}

Seven sociodemographic, 13 physical health, 11 social environmental, 56 clinical psychiatric, 14 cognitive functioning, 88 neuroimaging and five genetic variables were included (Table 1), based on available literature, as predictors of group status (for a detailed overview of all included measures please see Supplemental Note 5 and Supplemental Table S1). 


\section{Statistical analysis}

\section{Training and independent replication datasets}

In order to perform the binomial penalized logistic regression analysis, a training dataset, consisting of $2 / 3$ of the data, and a validation dataset, consisting of $1 / 3$ of the data, were created by randomly splitting the data according to the data collection site to ensure the generalization of model performance to independent sites (see Supplemental Table S2 and Figure 1).

\section{Classification of group status in the training set}

Binomial penalized logistic regression analysis was performed using the package glmnet in $\mathrm{R}$

[13]. This was applied to a combination of all predictors in the training set to distinguish between (1) the healthy control group; (2) the clinical control group and (3) the STB group. The binomial penalized logistic regression builds a sparse model by adding a penalty which prevents overfitting. This approach combines two types of penalties or regularizations. A Ridge penalty shrinks coefficients, making their contribution to the model small, and a Lasso penalty forces some coefficients to zero, meaning that the feature is not selected for the model. A combination of the two penalties allows for feature selection as well as for features to have a small contribution to the model. Binomial penalized regression was performed with different penalties (alpha levels: $0.25,0.5,0.75$ and 1 ), varying between a Lasso penalty (alpha=1) and a combination of Lasso and Ridge penalties (elastic net; alpha's between 0.25 and 0.75 ). Ten-fold cross-validation (CV) was applied by dividing the training dataset into 10 sets, and within each CV fold, 9 out of 10 sets were combined to form the training set and 1 was used as the test set. This was repeated 10 times. The glmnet package determined the optimal lambda value by identifying the lambda associated with the minimum Brier score. In each CV fold, we imputed missing values using the caret package [14] in the test set and training set separately, in order to prevent data leakage. Binomial analyses comparing two groups were run (HC vs. CC, CC vs. 
STB and HC vs STB groups). Binomial analyses were performed instead of multinomial analyses, as a set of clinical psychiatric measures were only non-zero in the CC and STB groups. As the STB group was smaller than the clinical control and healthy control groups, we under-sampled these larger groups within each CV fold to match the size of the STB group.

The performance of the model was assessed using the area under the receiver operating characteristics curve (AUROC). AUROC represents the proportion of times an individual from a positive class (e.g. STB group) is ranked below an individual from a negative class (e.g. HC). In addition, sensitivity, specificity, average of the sensitivity and specificity (accuracy) were calculated. Permutation testing (by comparing the AUROC against the AUROC of the same procedure repeated 1000 with permuted group labels) was used to examine if the model performed significantly above chance level classification. To identify the features that contributed most to the predictive model, the features that had a coefficient of more than 0 in at least $90 \%$ of the subsamples were selected.

\section{Generalization to the independent validation set}

The features that were selected in at least $90 \%$ of the subsamples at each alpha $(0.25,0.50$, $0.75,1.00)$ in the training dataset were used to predict group membership in the independent validation set. This validation set consisted of sites from the ABCD study that were kept separate to ensure independence. This analysis was done to test the generalizability of the predictive model to independent sites and participants. The selected features at each alpha were used in a Ridge logistic regression in the whole training set; this model was then tested on the independent validation set.

Modality-specific classification 
In order to examine the individual contribution of the different modalities to the classification of the STB groups, we repeated the aforementioned analysis, but only including specific types of predictors, thus performing separate analyses for sociodemographic, physical health, social environmental, clinical psychiatric, cognitive functioning, neuroimaging and genetic predictors.

Factors that differentiate ideators from attempters

To examine which factors differentiate between children with a history of attempt from those with suicidal ideation but no history of suicide attempt, the abovementioned binomial penalized logistic regression analysis was performed again with a different outcome variable. For this analysis, the dataset was again divided into a training set and validation set using the same site split as in the main analysis, and the same approach (including the binomial penalized logistic regression with $\mathrm{CV}$, feature selection and Ridge regression) was used to test generalizability; however, only 5 folds were used because the sample size was smaller.

\section{Results}

\section{Sample characteristics}

Age, sex, lifetime psychiatric diagnosis and self-reported suicidal thoughts or behaviors are presented in Table 2 for the three groups (healthy controls, clinical controls, and STB) based on child-reported suicidal thoughts or behaviors. In Table 3, age, sex, lifetime diagnosis and parent-reported suicidal thoughts and behaviors presented for the STB groups based on the parent-reported of suicidal thoughts and behaviors are reported.

\section{Classification of STB group}

\section{Classification of STB group: Cross validation model performance}

Results of the analysis using the child-reported STB group measures are presented in Table 4. AUROC values were highest when differentiating the HC and STB groups (range: 0.79-0.80 
across the different alpha levels), and were lowest for the comparison between $\mathrm{HC}$ and $\mathrm{CC}$ groups (AUROC range: 0.68-0.69, Figure 2).

A similar pattern was observed for the results of the analyses using the parent-reported STB group measures (see Table 5), with the highest AUROC observed for the HC vs. STB comparison (range: $0.80-0.81$ ) and lowest for the HC vs. CC comparison (range: $0.68-0.69$ ).

\section{$\underline{\text { Feature selection }}$}

Results of the feature selection analysis are presented in Table S4 and S5 for the child-reported STB groups and parent-reported STB groups, respectively. While the same predictors were included in both analyses, the factors that distinguished the child-reported STB group from the clinical controls were race, family conflict, prodromal psychotic symptoms, impulsivity (UPPS-P negative urgency and lack of planning subscales) and the CBCL depression subscale score. The factors that differentiated the clinical controls from the parent-reported STB group included the CBCL depression subscales (anxious depression, DSM5 depression), CBCL conduct disorder subscale score, CBCL internalizing and externalizing broad band scores and a history of mental health treatment.

\section{Generalization to the independent validation dataset}

The AUROC in the independent validation dataset (separate ABCD sites) using the most contributing features selected (see above), was in line with the AUROCs achieved in the training dataset (see Supplemental Tables S6 and S7). Classifying HC vs. STB, the AUROC ranged between $0.78-0.80$ using the child-reported STB group measure and between $0.80-0.82$ using the parent-reported STB group measure, using the features that were selected in the training dataset at different alphas. Classifying $\mathrm{HC}$ vs. $\mathrm{CC}$, the AUROC ranged between 0.70-0.71 using the child-reported group measure and between 0.70-0.71 using the parent-reported measure. 
Finally, classifying CC vs. STB, the AUROC ranged between 0.68-0.72 when using the childreported measure and between 0.70-0.71 when using the parent-reported measure.

\section{Modality-specific classification}

Results of these analyses are presented in Table S8 and S9 for the child-reported and parentreported STB group analyses, respectively. For both the classification of the child- and parent reported STB group status, the clinical psychiatric (AUROC range child-reported: 0.67-0.69; parent-reported: 0.76-0.79), physical health (AUROC range child-reported: 0.58-0.73; parentreported: 0.63-0.78), cognitive functioning (AUROC range child-reported: 0.58-0.72; parentreported: 0.54-0.65) and social environmental factors (AUROC range child-reported: 0.60-0.74; parent-reported: 0.60-0.71) best predicted STB group status, in contrast to neuroimaging (AUROC range child-reported: 0.49-0.54; parent-reported: 0.50-0.53), sociodemographic measures (AUROC range child-reported: 0.53-0.59; parent-reported: 0.53-0.62) and genetic characteristics (AUROC range child-reported: 0.51-0.57; parent-reported: 0.52-0.56). Similar to the aforementioned results, the highest AUROC values were observed for the HC vs. STB comparison.

\section{Classification of ideators versus attempters}

Results of the analysis used to classify child-reported suicidal ideation versus suicidal attempt are presented in Table 6. AUROC values varied between 0.54 and 0.59 across the different alpha levels. Results of the same analysis, but using the parent-reported group measure showed similar results (AUROC range: 0.49-0.54; see Table 7). As the results show that it is not possible to distinguish these two groups, no further feature selection or modality specific classification was performed.

\section{Discussion}


In a large sample of almost 6,000 unrelated children, we examined whether a combination of different predictors (sociodemographic, physical health, clinical psychiatric, cognitive, psychosocial, neuroimaging and genetic factors) could differentiate healthy children, children with psychiatric disorder but no history of suicidal thoughts or behavior, and children with a lifetime history of suicidal thoughts or suicide attempt (the STB group). Binomial penalized logistic regression analysis showed that the STB group could be distinguished from the HC and CC groups (AUROC range $0.79-0.81$ and $0.70-0.78$ respectively), but the ability to differentiate the $\mathrm{CC}$ and $\mathrm{HC}$ group was less accurate (AUROC range 0.68-0.69). These results may be explained by the fact that the children with most severe psychiatric symptoms may have been included in the STB group, thereby reducing the differences between the CC and HC groups. Our model generalized to independent data (separate ABCD recruitment sites (AUROC range 0.68-0.82)). The analyses for groups based on parent- and child-reported measures were performed separately, as a recent study [5] showed low correspondence between parentreported and child-reported measures of suicidal thoughts and behaviors in the ABCD study. The AUROCs of these analyses were very similar, as we were able to distinguish the groups based on both the parent- and child-reported measures. Children with a lifetime history of suicidal ideation could not be distinguished from those with a lifetime history of suicide attempt (AUROC range 0.49-0.59).

The classification of STB and identifying contributing risk factors are important aims in suicide research as it may help identify those at risk and help target prevention and intervention efforts. We were able to classify the STB group from the CC group with sensitivity between 0.59 and 0.65 , and specificity between 0.69 and 0.77 . This means that 2 out of 5 children with suicidal thoughts or behavior would be missed, and 1-2 out of 5 children would be considered to have suicidal thoughts or behavior when they do not. This sensitivity is lower than the sensitivity of existing suicide scales in predicting suicide attempt $[15,16]$, and not yet sufficient to be used 
medRxiv preprint doi: https://doi.org/10.1101/2021.02.15.21251736; this version posted February 19, 2021. The copyright holder for this preprint (which was not certified by peer review) is the author/funder, who has granted medRxiv a license to display the preprint in perpetuity.

All rights reserved. No reuse allowed without permission.

as a clinical decision tool. Our findings are in line with three meta-analyses that showed that (a combination of) psychological or biological measures were limited in their ability to predict suicide or suicidal behavior [16-18] showing that classification of suicidal thoughts and behaviors is complex, and adding to the current debate around precision medicine in suicide research [e.g. 19].

When the risk factors were divided into separate modalities to examine their unimodal predictive characteristics, the AUROC values for social environmental, physical, cognitive, and clinical psychiatric modalities were higher than the AUROC values for neuroimaging, genetic and sociodemographic modalities. This finding was in line with the strongest contributing features when all predictors were combined in one analysis, as these features were mainly from the social environmental, and clinical psychiatric categories. The fMRI-based measures included did not seem to contribute to the classification of children with STB In contrast to these findings, previous studies have found that functional brain alterations in the prefrontal cortex are related to STB [20, 21] and contribute to the classification of suicidal youth [22]. However, our findings are consistent with a neuroimaging-specific evaluation of this same cohort, in which no association was found between suicidal thoughts and behaviors and functional neuroimaging measures [23]. These discrepant findings between ABCD and other studies could potentially be explained by the younger age of participants in the ABCD study, the fact that $A B C D$ is a population study, or methodological issues that have been described elsewhere [24].

Most features that contributed to the model classifying HC and STB also contributed when classifying CC from HC. When the STB group was differentiated from the CC group, family conflict, prodromal psychosis, severity of mental health symptoms and measures of impulsivity were amongst the features that contributed most to the model's predictions. These findings highlight the potential need for clinicians to consider alternative interventions, including 
family-based psychological interventions to decrease family conflict [25] or neuropsychological training to increase cognitive control and planning abilities; and emotional regulation skills, distress tolerance training or mindfulness based interventions in order to decrease negative urgency and modulate impulsivity in suicidal individuals. Surprisingly, parent-reported child mental health service use, predicted parent-reported STB, but not child-reported STB, further highlighting the low correspondence between parent- and child-reported STB.

Understanding which children will experience suicidal thoughts or attempt suicide has important implications for suicide prevention and clinical practice [26]. In this cross-sectional study, we were unable to differentiate children with suicidal thoughts from children with a history of suicidal behavior, potentially suggesting a shared etiology between ideation and attempt in this age group. A large study in 16 year-olds showed that, compared to adolescents with suicidal thoughts, those that attempted suicide were more often exposed to self-harm by friends or family members, were more likely to be diagnosed with a psychiatric disorder, more often were female, exposed to trauma, more impulsive and had specific personality characteristics (i.e. high sensation seeking and low conscientiousness) [27]. A second large study conducted among adolescents and young adults showed that acquired capability, impulsivity, mental imagery about death and exposure to suicidal behavior were more common in those who attempted suicide compared to ideators [10]. Meta-analyses showed that traumatic life events, history of abuse, drug use disorders, and alterations in decision making and impulsivity were more common in attempters than ideators, while depression, alcohol use, hopelessness, and sociodemographic variables did not differ between attempters and ideators $[28,29]$. We were unable to include most of the aforementioned variables in our logistic regression model, which may explain why our classification performance was poorer than that observed in previous studies. The variables that contributed to the classification of STB from CC, were unable to distinguish ideation from an attempt, as they may be related to suicidal thoughts and behavior in 
general, and do not differ between ideators and attempters. In addition, only 67 children reported a history of suicide attempt and only 30 parents reported that their child had a history of suicide attempt, which may have limited our power to detect small effects. Finally, the young age of these participants may have added additional noise to the classification, as a larger fraction of the ideation group may attempt suicide in the future compared to studies with older participants.

This is the first study to combine multimodal features to classify children with suicidal thoughts and behavior from the $\mathrm{CC}$ and $\mathrm{HC}$ participants in the ABCD study, and builds on previous work by Janiri et al. and DeVille et al. [5, 6]. Strengths of this study include the large sample size of unrelated participants, the availability of many different types of predictors, including clinical, sociodemographic, biological and cognitive measures, and the use of an ecologically valid control group consisting of children with a psychiatric disorder. An additional strength is rigorous validation using cross validation and an independent out of sample validation which avoids overly optimistic results due to overfitting in the training set. The findings need to be interpreted in the light of a few limitations, including the cross-sectional nature of the data. Longitudinal data collection for participants enrolled in the ABCD study is planned at 2 year intervals for a total of 10 years, and future studies may build on these baseline models to predict suicidal thoughts or behavior throughout adolescence. Finally, no measures of the severity or frequency of suicidal ideation or behavior were available, which limited our ability to examine specific subgroups with varying suicidal severity.

Identifying factors that differentiate children with psychiatric disorder with and without a history of suicidal thoughts or behavior can inform risk assessments and identify new treatment targets. Our study shows that social environment (family conflict), cognitive (impulsivity) and clinical measures (e.g. severity of prodromal psychosis symptoms, severity of depression) 
medRxiv preprint doi: https://doi.org/10.1101/2021.02.15.21251736; this version posted February 19, 2021. The copyright holder for this preprint (which was not certified by peer review) is the author/funder, who has granted medRxiv a license to display the preprint in perpetuity.

All rights reserved. No reuse allowed without permission.

differentiate children with and without a history of suicidal thoughts and behavior. More studies in a larger sample of attempters are needed to confirm whether the factors identified in our study differentiate those with ideation from those with a history of attempt and prospectively predict subsequent suicidal behavior. In addition, future studies could determine whether including additional variables (e.g., trauma-related variables or suicide-related measures) improves classification. This work highlights the need for clinicians to monitor children who present multiple risk factors and may inform future socio-environmental interventions that may contribute to suicide prevention in at-risk children.

\section{Acknowledgements}

This work was supported by the MQ Brighter Futures Award MQBFC/2 (LS) and the National Institute of Mental Health of the National Institutes of Health under Award Number R01MH117601 (LS, NJ). LS is supported by a NHMRC Career Development Fellowship (1140764).

Data used in the preparation of this article were obtained from the Adolescent Brain Cognitive Development ${ }^{\mathrm{SM}}(\mathrm{ABCD})$ study (https://abcdstudy.org), held in the NIMH Data Archive (NDA).

This is a multisite, longitudinal study designed to recruit more than 10,000 children age $9-10$ and follow them over 10 years into early adulthood. The ABCD Study® is supported by the National Institutes of Health and additional federal partners under award numbers U01DA0401048, U01DA050989, U01DA051016, U01DA041022, U01DA051018, U01DA051037, U01DA050987, U01DA041174, U01DA041106, U01DA041117, U01DA041028, U01DA041134, U01DA050988, U01DA051039, U01DA041156, U01DA041025, U01DA041120, U01DA051038, U01DA041148, U01DA041093, U01DA041089, U24DA041123, U24DA041147. A full list of supporters is available at https://abcdstudy.org/federal-partners.html. A listing of participating sites and a complete listing of the study investigators can be found at 
medRxiv preprint doi: https://doi.org/10.1101/2021.02.15.21251736; this version posted February 19, 2021. The copyright holder for this preprint (which was not certified by peer review) is the author/funder, who has granted medRxiv a license to display the preprint in perpetuity. All rights reserved. No reuse allowed without permission.

https://abcdstudy.org/consortium members/. ABCD consortium investigators designed and implemented the study and/or provided data but did not necessarily participate in analysis or writing of this report. This manuscript reflects the views of the authors and may not reflect the opinions or views of the $\mathrm{NIH}$ or $A B C D$ consortium investigators. The ABCD repository grows and changes over time. The ABCD data used in this report came from 10.15154/1520786. DOls can be found at nda.nih.gov.

\section{Conflict of interests}

The authors declare no competing financial interests. 
Table 1. ABCD measures included in this study per domain

\begin{tabular}{|c|c|c|c|c|c|c|}
\hline Sociodemographic & $\begin{array}{l}\text { Physical } \\
\text { health }\end{array}$ & $\begin{array}{l}\text { Social } \\
\text { environmental }\end{array}$ & $\begin{array}{l}\text { Clinical } \\
\text { psychiatric }{ }^{\#}\end{array}$ & Cognition & Neuroimaging & Genetic \\
\hline Age & $\begin{array}{l}\text { Physical } \\
\text { illness }\end{array}$ & $\begin{array}{l}\text { Parental } \\
\text { monitoring }\end{array}$ & $\begin{array}{l}\text { CBCL psychiatric } \\
\text { items ( } 17 \text { subscale } \\
\text { scores, } 2 \text { broadband } \\
\text { scores and } 1 \text { total } \\
\text { score) }\end{array}$ & $\begin{array}{l}\text { Flanker } \\
\text { inhibitory } \\
\text { control task }\end{array}$ & $\begin{array}{l}\text { Stop signal task } \\
\text { correct stop vs } \\
\text { correct go in } 22 \\
\text { ROls }\end{array}$ & $\begin{array}{l}\text { Polygenic } \\
\text { risk scores } \\
\text { (MDD, BD, } \\
\text { AN, SZ \& } \\
\text { CD) }\end{array}$ \\
\hline Sex & $\begin{array}{l}\text { Pubertal } \\
\text { status }\end{array}$ & Family conflict & Prodromal psychosis & $\begin{array}{l}\text { Card sorting } \\
\text { task }\end{array}$ & $\begin{array}{l}\text { Monetary } \\
\text { Incentive Delay } \\
\text { task - reward vs } \\
\text { neutral in } 34 \\
\text { ROls }\end{array}$ & \\
\hline $\begin{array}{l}\text { Parental marital } \\
\text { status }\end{array}$ & $\begin{array}{l}\text { Sleep } \\
\text { quality }\end{array}$ & $\begin{array}{l}\text { Prosocial } \\
\text { behavior }\end{array}$ & Mania symptoms & $\begin{array}{l}\text { Cash-choice } \\
\text { task }\end{array}$ & $\begin{array}{l}\text { Monetary } \\
\text { Incentive Delay } \\
\text { task - loss vs } \\
\text { neutral in } 32 \\
\text { ROIs }\end{array}$ & \\
\hline $\begin{array}{l}\text { Family income in the } \\
\text { last } 12 \text { months }\end{array}$ & $\begin{array}{l}\text { Physical } \\
\text { activity }\end{array}$ & $\begin{array}{l}\text { Parental } \\
\text { acceptance }\end{array}$ & $\begin{array}{l}\text { Mental health } \\
\text { service use }\end{array}$ & Impulsivity & & \\
\hline Parental education & BMI & Bullying & $\begin{array}{l}\text { Current psychiatric } \\
\text { diagnosis parent } \\
\text { report } \%^{\circ}\end{array}$ & $\begin{array}{l}\text { Picture } \\
\text { vocabulary } \\
\text { task }\end{array}$ & & \\
\hline Race of the child & $\begin{array}{l}\text { Screen } \\
\text { time }\end{array}$ & $\begin{array}{l}\text { Friendships (best } \\
\text { friend \& friend } \\
\text { group) }\end{array}$ & $\begin{array}{l}\text { Lifetime psychiatric } \\
\text { diagnosis parent } \\
\text { report } \%^{\text {a }}\end{array}$ & $\begin{array}{l}\text { List sorting } \\
\text { task }\end{array}$ & & \\
\hline \multirow[t]{4}{*}{$\begin{array}{l}\text { Number of co- } \\
\text { habitants at home }\end{array}$} & & $\begin{array}{l}\text { Neighborhood } \\
\text { safety }\end{array}$ & $\begin{array}{l}\text { Psychiatric } \\
\text { diagnosis child } \\
\text { report }^{\wedge}\end{array}$ & $\begin{array}{l}\text { Pattern } \\
\text { comparison } \\
\text { task }\end{array}$ & & \\
\hline & & $\begin{array}{l}\text { School } \\
\text { environment, } \\
\text { involvement, } \\
\text { disengagement }\end{array}$ & $\begin{array}{l}\text { Family history of } \\
\text { psychopathology }\end{array}$ & $\begin{array}{l}\text { Picture } \\
\text { sequence } \\
\text { memory } \\
\text { task }\end{array}$ & & \\
\hline & & & & Reading test & & \\
\hline & & & & $\begin{array}{l}\text { Matrix } \\
\text { reasoning } \\
\text { task }\end{array}$ & & \\
\hline
\end{tabular}

\# These measures are only included in analyses comparing the CC \& STB group

$\%$ Diagnoses include: bipolar disorder, depressive disorder, psychotic disorder, attention-deficit hyperactivity disorder, panic disorder, social anxiety, specific phobia, generalized anxiety disorder, substance use disorder, obsessive compulsive disorder, posttraumatic stress disorder and eating disorder.

^ Diagnoses include: depressive disorder, bipolar disorder and anxiety disorders

AN: Anorexia; BD: bipolar disorder; CBCL: Achenbach Child Behaviour Checklist; CD: cross-disorder; MDD: major depressive disorder, SZ: schizophrenia 
Table 2. Sample characteristics for the child-reported STB group

\begin{tabular}{|c|c|c|c|}
\hline & $\begin{array}{l}\text { Healthy controls } \\
\qquad \mathrm{N}=2367\end{array}$ & $\begin{array}{l}\text { Clinical controls } \\
\quad \mathrm{N}=2985\end{array}$ & $\begin{array}{c}\text { Suicidal } \\
\text { ideation/attempt } \\
N=528\end{array}$ \\
\hline Age (in months) (SD) & $119(7.44)$ & $119(7.38)$ & $119(7.52)$ \\
\hline Sex (\% female) & $52.9 \%$ & $47.5 \%$ & $45.1 \%$ \\
\hline Lifetime BD (parent-reported) & NA & $297(9.9 \%)$ & $44(8.3 \%)$ \\
\hline Lifetime BD (child-reported) & NA & $394(13.2 \%)$ & $113(21.4 \%)$ \\
\hline Lifetime DD (parent-reported) & NA & $289(9.7 \%)$ & $62(11.7 \%)$ \\
\hline Lifetime DD (child-reported) & NA & $192(6.4 \%)$ & $74(14.0 \%)$ \\
\hline Lifetime ADHD (parent-reported) & NA & $956(32.0 \%)$ & $154(29.2 \%)$ \\
\hline Lifetime Psychotic disorder (parent-reported) & NA & $120(4.0 \%)$ & $19(3.6 \%)$ \\
\hline Lifetime Panic disorder (parent-reported) & NA & $41(1.4 \%)$ & $10(1.9 \%)$ \\
\hline Lifetime Social anxiety (parent-reported) & NA & $278(9.3 \%)$ & $35(6.6 \%)$ \\
\hline Lifetime Eating disorder (parent-reported) & NA & $549(18.4 \%)$ & $56(10.6 \%)$ \\
\hline Lifetime Specific phobia (parent-reported) & NA & $1413(47.3 \%)$ & $162(30.7 \%)$ \\
\hline Lifetime GAD (parent-reported) & NA & $290(9.7 \%)$ & $60(11.4 \%)$ \\
\hline Lifetime ANX (child-reported) & NA & $127(4.3 \%)$ & $49(9.3 \%)$ \\
\hline Lifetime OCD (parent-reported) & NA & $478(16.0 \%)$ & $87(16.5 \%)$ \\
\hline Lifetime PTSD (parent-reported) & NA & $197(6.6 \%)$ & $60(11.4 \%)$ \\
\hline Lifetime Substance use disorder (parent-reported) & NA & $8(0.3 \%)$ & $1(0.2 \%)$ \\
\hline Lifetime passive suicidal ideation (child-reported) & NA & NA & $386(73.1 \%)$ \\
\hline Lifetime active non-specific suicidal ideation (child-reported) & NA & NA & $275(52.1 \%)$ \\
\hline Lifetime active suicidal ideation + method (child-reported) & NA & NA & $77(14.6 \%)$ \\
\hline Lifetime active suicidal ideation + intent (child-reported) & NA & NA & $35(6.6 \%)$ \\
\hline Lifetime active suicidal ideation + plan (child-reported) & NA & NA & $28(5.3 \%)$ \\
\hline $\begin{array}{l}\text { Lifetime preparatory actions toward suicidal behavior (child- } \\
\text { reported) }\end{array}$ & NA & NA & $24(4.5 \%)$ \\
\hline Lifetime interrupted suicide attempt (child-reported) & NA & NA & $8(1.5 \%)$ \\
\hline Lifetime aborted suicide attempt (child-reported) & NA & NA & $28(5.3 \%)$ \\
\hline Lifetime actual suicide attempt (child-reported) & NA & NA & $37(7.0 \%)$ \\
\hline
\end{tabular}

Note: ADHD: Attention Deficit Hyperactivity Disorder; ANX: anxiety disorder; BD: bipolar disorder; DD: depressive disorder; GAD: generalized anxiety disorder; OCD: obsessive-compulsive disorder; PTSD: post-traumatic stress disorder; SD: standard deviation 
Table 3. Sample characteristics for the parent-reported STB group

\begin{tabular}{|c|c|c|c|}
\hline & $\begin{array}{l}\text { Healthy controls } \\
\qquad N=2415\end{array}$ & $\begin{array}{l}\text { Clinical controls } \\
\qquad N=2976\end{array}$ & $\begin{array}{l}\text { Suicidal } \\
\text { ideation/attempt } \\
N=494\end{array}$ \\
\hline Age (in months) (SD) & $119(7.44)$ & $119(7.37)$ & $120(7.60)$ \\
\hline Sex (\% female) & $53.0 \%$ & $48.4 \%$ & $38.5 \%$ \\
\hline Lifetime BD (parent-reported) & $0(0 \%)$ & $275(9.2 \%)$ & $69(14.0 \%)$ \\
\hline Lifetime BD (child-reported) & $0(0 \%)$ & $435(14.6 \%)$ & $68(13.8 \%)$ \\
\hline Lifetime DD (parent-reported) & $0(0 \%)$ & $238(8.0 \%)$ & $115(23.3 \%)$ \\
\hline Lifetime DD (child-reported) & $0(0 \%)$ & $218(7.3 \%)$ & $43(8.7 \%)$ \\
\hline Lifetime ADHD (parent-reported) & $0(0 \%)$ & $911(30.6 \%)$ & $205(41.5 \%)$ \\
\hline Lifetime Psychotic disorder (parent-reported) & $0(0 \%)$ & $101(3.4 \%)$ & $38(7.7 \%)$ \\
\hline Lifetime Panic disorder (parent-reported) & $0(0 \%)$ & $33(1.1 \%)$ & $18(3.6 \%)$ \\
\hline Lifetime Social anxiety (parent-reported) & $0(0 \%)$ & $246(8.3 \%)$ & $67(13.6 \%)$ \\
\hline Lifetime Eating disorder (parent-reported) & $0(0 \%)$ & $558(18.8 \%)$ & $52(10.5 \%)$ \\
\hline Lifetime Specific phobia (parent-reported) & $0(0 \%)$ & $1380(46.4 \%)$ & $199(40.3 \%)$ \\
\hline Lifetime GAD (parent-reported) & $0(0 \%)$ & $244(8.2 \%)$ & $107(21.7 \%)$ \\
\hline Lifetime ANX (child-reported) & $0(0 \%)$ & $150(5.0 \%)$ & $26(5.3 \%)$ \\
\hline Lifetime OCD (parent-reported) & $0(0 \%)$ & $461(15.5 \%)$ & $108(21.9 \%)$ \\
\hline Lifetime PTSD (parent-reported) & $0(0 \%)$ & $172(5.8 \%)$ & $86(17.4 \%)$ \\
\hline Lifetime Substance use disorder (parent-reported) & $0(0 \%)$ & $6(0.2 \%)$ & $3(0.6 \%)$ \\
\hline Lifetime passive suicidal ideation (parent-reported) & $0(0 \%)$ & $0(0 \%)$ & $423(85.6 \%)$ \\
\hline Lifetime active non-specific suicidal ideation (parent-reported) & $0(0 \%)$ & $0(0 \%)$ & $232(47.0 \%)$ \\
\hline Lifetime active suicidal ideation + method (parent-reported) & $0(0 \%)$ & $0(0 \%)$ & $59(11.9 \%)$ \\
\hline Lifetime active suicidal ideation + intent (parent-reported) & $0(0 \%)$ & $0(0 \%)$ & $27(5.5 \%)$ \\
\hline Lifetime active suicidal ideation + plan (parent-reported) & $0(0 \%)$ & $0(0 \%)$ & $10(2.0 \%)$ \\
\hline $\begin{array}{l}\text { Lifetime preparatory actions toward suicidal behavior (parent- } \\
\text { reported) }\end{array}$ & $0(0 \%)$ & $0(0 \%)$ & $33(6.7 \%)$ \\
\hline Lifetime interrupted suicide attempt (parent-reported) & $0(0 \%)$ & $0(0 \%)$ & $4(0.8 \%)$ \\
\hline Lifetime aborted suicide attempt (parent-reported) & $0(0 \%)$ & $0(0 \%)$ & $6(1.2 \%)$ \\
\hline Lifetime actual suicide attempt (parent-reported) & $0(0 \%)$ & $0(0 \%)$ & $23(4.7 \%)$ \\
\hline
\end{tabular}

Note. ADHD: Attention Deficit Hyperactivity Disorder; ANX: anxiety disorder; BD: bipolar disorder; DD: depressive disorder; GAD: generalized anxiety disorder; OCD: obsessive-compulsive disorder; PTSD: post-traumatic stress disorder; SD: standard deviation 
medRxiv preprint doi: https://doi.org/10.1101/2021.02.15.21251736; this version posted February 19, 2021. The copyright holder for this preprint (which was not certified by peer review) is the author/funder, who has granted medRxiv a license to display the preprint in perpetuity.

All rights reserved. No reuse allowed without permission.

Table 4. Classification of STB groups (child-reported): Results of binomial penalized logistic regression analysis

\begin{tabular}{|c|c|c|c|c|c|c|}
\hline Comparison & Alpha & AUROC & SD AUROC & Sensitivity & Specificity & Accuracy \\
\hline \multicolumn{7}{|l|}{ HC vs. CC } \\
\hline & 0.25 & 0.686 & 0.022 & 0.691 & 0.578 & 0.634 \\
\hline & 0.50 & 0.686 & 0.027 & 0.694 & 0.579 & 0.637 \\
\hline & 0.75 & 0.687 & 0.029 & 0.694 & 0.576 & 0.635 \\
\hline & 1.00 & 0.686 & 0.027 & 0.694 & 0.575 & 0.634 \\
\hline \multicolumn{7}{|l|}{ HC vs. STB } \\
\hline & 0.25 & 0.795 & 0.041 & 0.686 & 0.766 & 0.726 \\
\hline & 0.50 & 0.797 & 0.046 & 0.688 & 0.777 & 0.732 \\
\hline & 0.75 & 0.796 & 0.048 & 0.684 & 0.762 & 0.723 \\
\hline & 1.00 & 0.798 & 0.048 & 0.682 & 0.767 & 0.725 \\
\hline \multicolumn{7}{|l|}{ CC vs. STB } \\
\hline & 0.25 & 0.706 & 0.053 & 0.597 & 0.693 & 0.645 \\
\hline & 0.50 & 0.714 & 0.059 & 0.602 & 0.708 & 0.655 \\
\hline & 0.75 & 0.708 & 0.058 & 0.601 & 0.697 & 0.649 \\
\hline & 1.00 & 0.714 & 0.060 & 0.600 & 0.710 & 0.655 \\
\hline
\end{tabular}

Note: CC: clinical control group; HC: healthy control group; STB: suicidal thoughts and behaviors group 
medRxiv preprint doi: https://doi.org/10.1101/2021.02.15.21251736; this version posted February 19, 2021. The copyright holder for this preprint (which was not certified by peer review) is the author/funder, who has granted medRxiv a license to display the preprint in perpetuity. All rights reserved. No reuse allowed without permission.

Table 5. Classification of STB groups (parent-reported): Results of binomial penalized binomial logistic regression analysis

\begin{tabular}{|c|c|c|c|c|c|c|}
\hline Comparison & Alpha & AUROC & SD AUROC & Sensitivity & Specificity & Accuracy \\
\hline \multicolumn{7}{|l|}{$\mathrm{HC}$ vs. $\mathrm{CC}$} \\
\hline & 0.25 & 0.682 & 0.027 & 0.027 & 0.027 & 0.027 \\
\hline & 0.50 & 0.684 & 0.028 & 0.028 & 0.028 & 0.028 \\
\hline & 0.75 & 0.684 & 0.030 & 0.030 & 0.030 & 0.030 \\
\hline & 1.00 & & & & & \\
\hline & & 0.684 & 0.026 & 0.026 & 0.026 & 0.026 \\
\hline \multicolumn{7}{|l|}{ HC vs. STB } \\
\hline & 0.25 & 0.806 & 0.046 & 0.662 & 0.794 & 0.728 \\
\hline & 0.50 & 0.807 & 0.047 & 0.663 & 0.794 & 0.729 \\
\hline & 0.75 & 0.804 & 0.048 & 0.663 & 0.792 & 0.727 \\
\hline & 1.00 & 0.804 & 0.049 & 0.655 & 0.788 & 0.721 \\
\hline \multicolumn{7}{|l|}{ CC vs. STB } \\
\hline & 0.25 & 0.765 & 0.057 & 0.635 & 0.745 & 0.690 \\
\hline & 0.50 & 0.769 & 0.051 & 0.643 & 0.759 & 0.701 \\
\hline & 0.75 & 0.761 & 0.052 & 0.643 & 0.746 & 0.694 \\
\hline & 1.00 & 0.775 & 0.049 & 0.646 & 0.760 & 0.703 \\
\hline
\end{tabular}

Note: CC: clinical control group; HC: healthy control group; STB: suicidal thoughts and behaviors group 
medRxiv preprint doi: https://doi.org/10.1101/2021.02.15.21251736; this version posted February 19, 2021. The copyright holder for this preprint (which was not certified by peer review) is the author/funder, who has granted medRxiv a license to display the preprint in perpetuity.

All rights reserved. No reuse allowed without permission.

Table 6. Classification of ideation versus suicidal behavior (child-reported): Results of binomial penalized logistic regression analysis

\begin{tabular}{lcccccc}
\hline Comparison & Alpha & AUROC & SD AUROC & Sensitivity & Specificity & Accuracy \\
\hline Ideation versus suicidal behavior & & & & & \\
\cline { 2 - 7 } 0.25 & 0.589 & 0.148 & 0.655 & 0.468 & 0.562 \\
0.50 & 0.566 & 0.127 & 0.685 & 0.408 & 0.546 \\
0.75 & 0.547 & 0.120 & 0.712 & 0.368 & 0.540 \\
1.00 & 0.567 & 0.126 & 0.718 & 0.373 & 0.546 \\
\hline
\end{tabular}


medRxiv preprint doi: https://doi.org/10.1101/2021.02.15.21251736; this version posted February 19, 2021. The copyright holder for this preprint (which was not certified by peer review) is the author/funder, who has granted medRxiv a license to display the preprint in perpetuity.

All rights reserved. No reuse allowed without permission.

Table 7. Classification of ideation versus suicidal behavior (parent-reported): Results of binomial penalized logistic regression analysis

\begin{tabular}{|c|c|c|c|c|c|c|}
\hline Comparison & Alpha & AUROC & SD AUROC & Sensitivity & Specificity & Accuracy \\
\hline \multicolumn{7}{|c|}{ Ideation versus suicidal behavior } \\
\hline & 0.25 & 0.493 & 0.201 & 0.645 & 0.353 & 0.499 \\
\hline & 0.50 & 0.520 & 0.199 & 0.724 & 0.305 & 0.514 \\
\hline & 0.75 & 0.513 & 0.156 & 0.674 & 0.318 & 0.496 \\
\hline & 1.00 & 0.532 & 0.231 & 0.679 & 0.329 & 0.504 \\
\hline
\end{tabular}




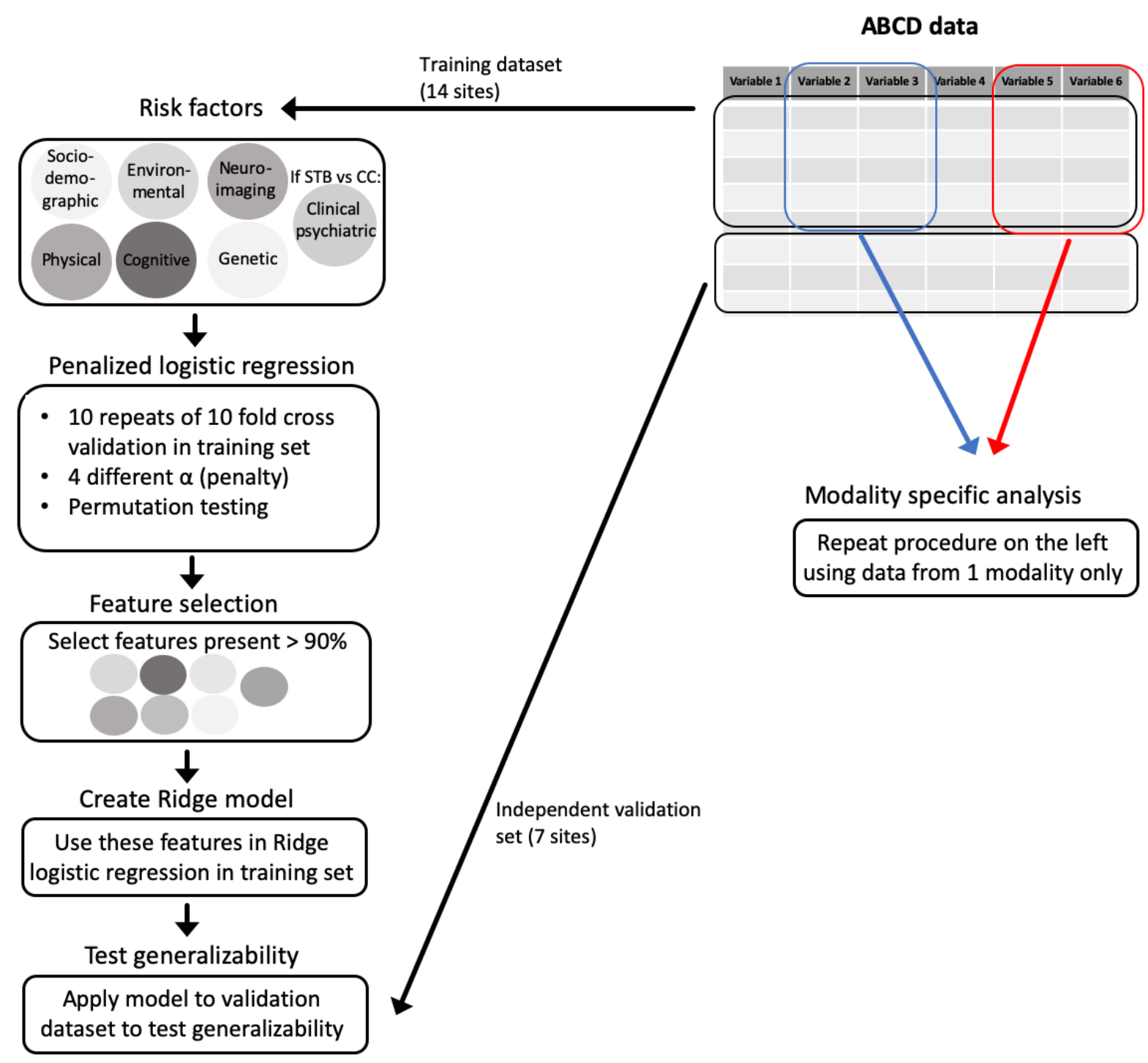

Figure 1. Flowchart to describe the analysis procedure. The ABCD data was split into a training and test set. The training set was used to do a penalized logistic regression in ten-fold cross validation and repeat this ten times with 4 different combinations of the Lasso and Ridge penalty. Features that had a coefficient higher than 0 in $90 \%$ or more of the repeats were selected to create a Ridge logistic regression to differentiate groups. This Ridge model was then tested on the test dataset. In addition, the same procedure was repeated only including risk factors from one modality. 
medRxiv preprint doi: https://doi.org/10.1101/2021.02.15.21251736; this version posted February 19, 2021. The copyright holder for this preprint (which was not certified by peer review) is the author/funder, who has granted medRxiv a license to display the preprint in perpetuity.

All rights reserved. No reuse allowed without permission.

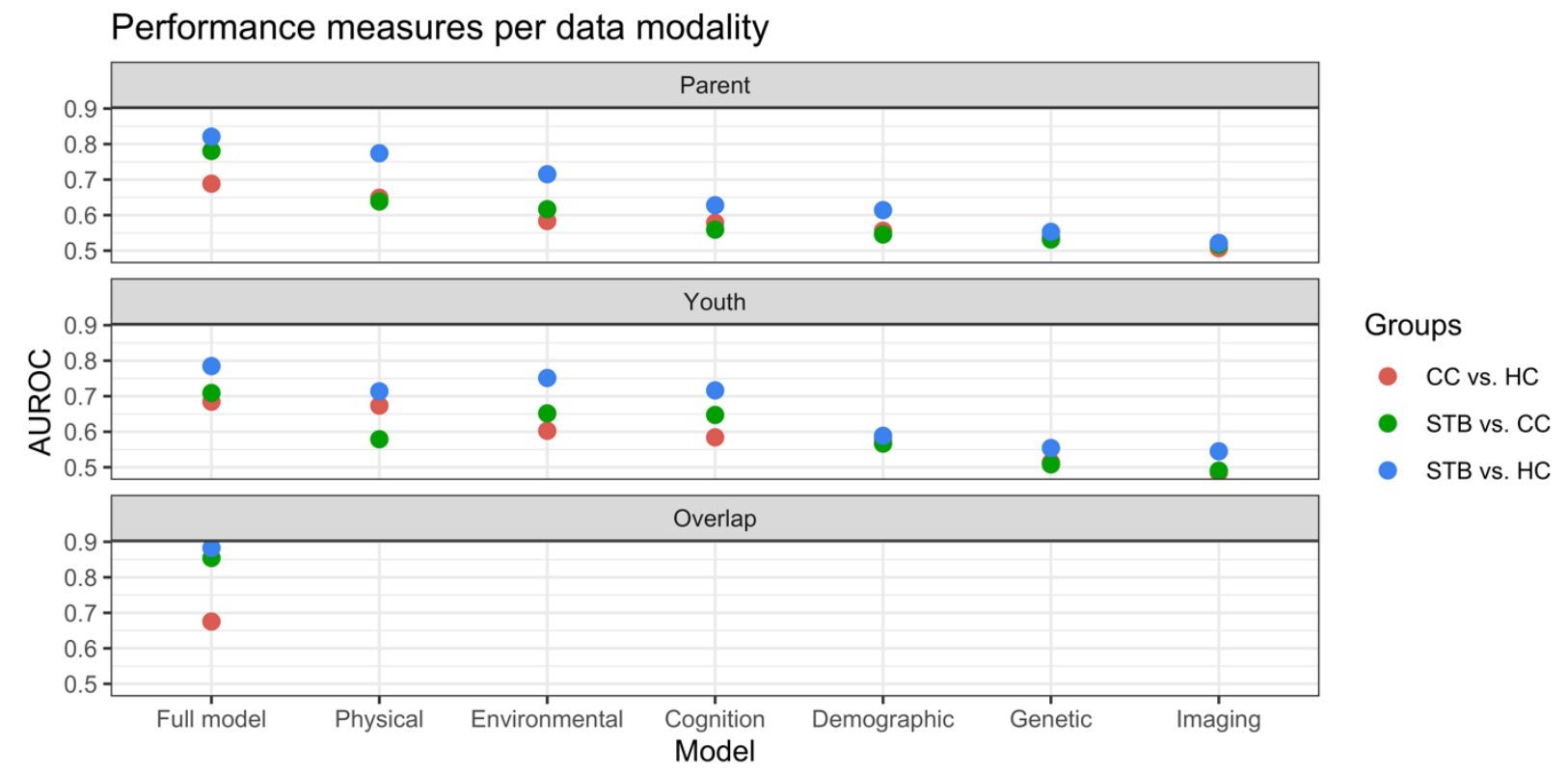

Figure 2. Average AUROC per data modality 
medRxiv preprint doi: https://doi.org/10.1101/2021.02.15.21251736; this version posted February 19, 2021. The copyright holder for this preprint (which was not certified by peer review) is the author/funder, who has granted medRxiv a license to display the preprint in perpetuity.

All rights reserved. No reuse allowed without permission.

\section{References}

1. Alicandro G, Malvezzi M, Gallus S, La Vecchia C, Negri E, Bertuccio P. Worldwide trends in suicide mortality from 1990 to 2015 with a focus on the global recession time frame. Int J Public Health. 2019;64:785-795.

2. Hawton K, Saunders KEA, O'Connor RC. Self-harm and suicide in adolescents. Lancet. 2012;379:2373-2382.

3. World Health Organization. Preventing suicide: A global imperative. World Health Organization; 2014.

4. Centers for Disease Control and Prevention (CDC). Web-based injury statistics query and reporting system (WISQARS). 2017.

5. Janiri D, Doucet GE, Pompili M, Sani G, Luna B, Brent DA, et al. Risk and protective factors for childhood suicidality: a US population-based study. Lancet Psychiatry. 2020;7:317-326.

6. DeVille DC, Whalen D, Breslin FJ, Morris AS, Khalsa SS, Paulus MP, et al. Prevalence and Family-Related Factors Associated With Suicidal Ideation, Suicide Attempts, and Self-injury in Children Aged 9 to 10 Years. JAMA Network Open. 2020;3:e1920956.

7. Volkow ND, Koob GF, Croyle RT, Bianchi DW, Gordon JA, Koroshetz WJ, et al. The conception of the ABCD study: From substance use to a broad NIH collaboration. Dev Cogn Neurosci. 2018;32:4-7.

8. Vargas-Medrano J, Diaz-Pacheco V, Castaneda C, Miranda-Arango M, Longhurst MO, Martin SL, et al. Psychological and neurobiological aspects of suicide in adolescents: Current outlooks. Brain Behav Immun Health. 2020;7:100124.

9. Klonsky ED, May AM. The Three-Step Theory (3ST): A New Theory of Suicide Rooted in the 'Ideation-to-Action' Framework. Int J Cogn Ther. 2015;8:114-129.

10. Wetherall K, Cleare S, Eschle S, Ferguson E, O'Connor DB, O'Carroll RE, et al. From ideation to action: Differentiating between those who think about suicide and those who attempt suicide in a national study of young adults. Journal of Affective Disorders. 2018;241:475-483.

11. Nock MK, Borges G, Bromet EJ, Alonso J, Angermeyer M, Beautrais A, et al. Crossnational prevalence and risk factors for suicidal ideation, plans and attempts. $\mathrm{Br} \mathrm{J}$ Psychiatry. 2008;192:98-105.

12. Kobak KA, Kratochvil CJ, Stanger C, Kaufman J. Computerized screening of comorbidity in adolescents with substance or psychiatric disorders. Anxiety Disorders and Depression (La Jolaa, CA). 2013.

13. Friedman J, Hastie T, Tibshirani R. Regularization paths for generalized linear models via coordinate descent. J Stat Softw. 2010;33:1.

14. Kuhn M, Others. Building predictive models in $\mathrm{R}$ using the caret package. J Stat Softw. 2008;28:1-26.

15. Lindh ÅU, Dahlin M, Beckman K, Strömsten L, Jokinen J, Wiktorsson S, et al. A Comparison of Suicide Risk Scales in Predicting Repeat Suicide Attempt and Suicide: A Clinical Cohort Study. J Clin Psychiatry. 2019;80.

16. Runeson B, Odeberg J, Pettersson A, Edbom T, Jildevik Adamsson I, Waern M. Instruments for the assessment of suicide risk: A systematic review evaluating the certainty of the evidence. PLoS One. 2017;12:e0180292.

17. Carter G, Milner A, McGill K, Pirkis J, Kapur N, Spittal MJ. Predicting suicidal behaviours using clinical instruments: systematic review and meta-analysis of positive predictive values for risk scales. Br J Psychiatry. 2017;210:387-395.

18. Belsher BE, Smolenski DJ, Pruitt LD, Bush NE, Beech EH, Workman DE, et al. Prediction Models for Suicide Attempts and Deaths: A Systematic Review and Simulation. JAMA Psychiatry. 2019;76:642-651.

19. Whiting D, Fazel S. How accurate are suicide risk prediction models? Asking the right 
medRxiv preprint doi: https://doi.org/10.1101/2021.02.15.21251736; this version posted February 19, 2021. The copyright holder for this preprint (which was not certified by peer review) is the author/funder, who has granted medRxiv a license to display the preprint in perpetuity. All rights reserved. No reuse allowed without permission.

questions for clinical practice. Evid Based Ment Health. 2019;22:125-128.

20. Schmaal L, van Harmelen A-L, Chatzi V, Lippard ETC, Toenders YJ, Averill LA, et al. Imaging suicidal thoughts and behaviors: a comprehensive review of 2 decades of neuroimaging studies. Mol Psychiatry. 2020;25:408-427.

21. Gosnell SN, Fowler JC, Salas R. Classifying suicidal behavior with resting-state functional connectivity and structural neuroimaging. Acta Psychiatr Scand. 2019;140:20-29.

22. Just MA, Pan L, Cherkassky VL, McMakin DL, Cha C, Nock MK, et al. Machine learning of neural representations of suicide and emotion concepts identifies suicidal youth. Nature Human Behaviour. 2017;1:911-919.

23. Vidal-Ribas P, Janiri D, Doucet GE, Pornpattananangkul N, Nielson DM, Frangou S, et al. Multimodal neuroimaging and suicidality in a US population-based sample of school-aged children.

24. Bissett PG, Hagen MP, Poldrack RA. A cautionary note on stop-signal data from the Adolescent Brain Cognitive Development [ABCD] study. 2020:2020.05.08.084707.

25. Weinstein SM, Cruz RA, Isaia AR, Peters AT, West AE. Child- and Family-Focused Cognitive Behavioral Therapy for Pediatric Bipolar Disorder: Applications for Suicide Prevention. Suicide Life Threat Behav. 2018;48:797-811.

26. Klonsky ED, Quu T, Saffer BY. Recent advances in differentiating suicide attempters from suicide ideators. Curr Opin Psychiatry. 2017;30:15-20.

27. Mars B, Heron J, Klonsky ED, Moran P, O'Connor RC, Tilling K, et al. What distinguishes adolescents with suicidal thoughts from those who have attempted suicide? A populationbased birth cohort study. J Child Psychol Psychiatry. 2019;60:91-99.

28. May AM, Klonsky ED. What distinguishes suicide attempters from suicide ideators? A meta-analysis of potential factors. Clinical Psychology: Science and Practice. 2016;23:520.

29. Saffer BY, Klonsky ED. Do neurocognitive abilities distinguish suicide attempters from suicide ideators? A systematic review of an emerging research area. Clin Psychol Sci Pract. 2018;25:e12227.

30. Stover PJ, Harlan WR, Hammond JA, Hendershot T, Hamilton CM. PhenX: a toolkit for interdisciplinary genetics research. Curr Opin Lipidol. 2010;21:136-140.

31. Petersen AC, Crockett L, Richards M, Boxer A. A self-report measure of pubertal status: Reliability, validity, and initial norms. J Youth Adolesc. 1988;17:117-133.

32. Bruni O, Ottaviano S, Guidetti V, Romoli M, Innocenzi M, Cortesi F, et al. The Sleep Disturbance Scale for Children (SDSC) Construct ion and validation of an instrument to evaluate sleep disturbances in childhood and adolescence. J Sleep Res. 1996;5:251-261.

33. Spruyt K, Gozal D. Pediatric sleep questionnaires as diagnostic or epidemiological tools: A review of currently available instruments. Sleep Med Rev. 2011;15:19-32.

34. CDC. Youth risk behavior survey (YRBS). 2019. 2019.

35. Todd RD, Joyner CA, Heath AC, Neuman RJ, Reich W. Reliability and stability of a semistructured DSM-IV interview designed for family studies. J Am Acad Child Adolesc Psychiatry. 2003;42:1460-1468.

36. Sharif I, Wills TA, Sargent JD. Effect of visual media use on school performance: a prospective study. J Adolesc Health. 2010;46:52-61.

37. PhenXToolkit. Neighborhood Safety (\#210900 \& 210901). 2016.

38. Moos R, Moos B. Family Environment Scale Manual. 1981. Palo Alto.

39. Goodman R, Meltzer H, Bailey V. The Strengths and Difficulties Questionnaire: a pilot study on the validity of the self-report version. Int Rev Psychiatry. 2003;15:173-177.

40. Schaefer ES. A configurational analysis of children's reports of parent behavior. J Consult Psychol. 1965;29:552-557.

41. Chilcoat HD, Anthony JC. Impact of parent monitoring on initiation of drug use through late childhood. J Am Acad Child Adolesc Psychiatry. 1996;35:91-100. 
medRxiv preprint doi: https://doi.org/10.1101/2021.02.15.21251736; this version posted February 19, 2021. The copyright holder for this preprint (which was not certified by peer review) is the author/funder, who has granted medRxiv a license to display the preprint in perpetuity. All rights reserved. No reuse allowed without permission.

42. PhenXToolkit. School Risk and Protective Factors (\#540500). 2016. 2016.

43. Achenbach TM. Achenbach System of Empirically Based Assessment (ASEBA): Development, Findings, Theory, and Applications. University of Vermont, Research Center of Children, Youth \& Families; 2009.

44. Brown SA, Brumback T, Tomlinson K, Cummins K, Thompson WK, Nagel BJ, et al. The National Consortium on Alcohol and NeuroDevelopment in Adolescence (NCANDA): A Multisite Study of Adolescent Development and Substance Use. J Stud Alcohol Drugs. 2015;76:895-908.

45. Youngstrom EA, Frazier TW, Demeter C, Calabrese JR, Findling RL. Developing a 10-item mania scale from the Parent General Behavior Inventory for children and adolescents. J Clin Psychiatry. 2008;69:831-839.

46. Loewy RL, Therman S, Manninen M, Huttunen MO, Cannon TD. Prodromal psychosis screening in adolescent psychiatry clinics. Early Interv Psychiatry. 2012;6:69-75.

47. Wechsler D. Wechsler Intelligence Scale for Children $®$, 5th ed. Pearson, Bloomington, MN; 2014.

48. Wulfert E, Block JA, Santa Ana E, Rodriguez ML, Colsman M. Delay of gratification: impulsive choices and problem behaviors in early and late adolescence. J Pers. 2002;70:533-552.

49. Zapolski TCB, Stairs AM, Settles RF, Combs JL, Smith GT. The measurement of dispositions to rash action in children. Assessment. 2010;17:116-125.

50. Lynam DR. Development of a short form of the UPPS-P Impulsive Behavior Scale. Unpublished Technical Report. 2013.

51. Casey BJ, Cannonier T, Conley MI, Cohen AO, Barch DM, Heitzeg MM, et al. The Adolescent Brain Cognitive Development (ABCD) study: Imaging acquisition across 21 sites. Dev Cogn Neurosci. 2018;32:43-54.

52. Zhang R, Geng X, Lee TMC. Large-scale functional neural network correlates of response inhibition: an fMRI meta-analysis. Brain Struct Funct. 2017;222:3973-3990.

53. Rae CL, Hughes LE, Weaver C, Anderson MC, Rowe JB. Selection and stopping in voluntary action: A meta-analysis and combined fMRI study. Neurolmage. 2014;86:381391.

54. Wilson RP, Colizzi M, Bossong MG, Allen P, Kempton M, MTAC, et al. The Neural Substrate of Reward Anticipation in Health: A Meta-Analysis of fMRI Findings in the Monetary Incentive Delay Task. Neuropsychol Rev. 2018;28:496-506.

55. Oldham S, Murawski C, Fornito A, Youssef G, Yücel M, Lorenzetti V. The anticipation and outcome phases of reward and loss processing: A neuroimaging meta-analysis of the monetary incentive delay task. Hum Brain Mapp. 2018;39:3398-3418.

56. Dugré JR, Dumais A, Bitar N, Potvin S. Loss anticipation and outcome during the Monetary Incentive Delay Task: a neuroimaging systematic review and meta-analysis. PeerJ. 2018;6:e4749.

57. Howard DM, Adams MJ, Clarke T-K, Hafferty JD, Gibson J, Shirali M, et al. Genome-wide meta-analysis of depression identifies 102 independent variants and highlights the importance of the prefrontal brain regions. Nat Neurosci. 2019;22:343-352.

58. Stahl EA, Breen G, Forstner AJ, McQuillin A, Ripke S, Trubetskoy V, et al. Genome-wide association study identifies 30 loci associated with bipolar disorder. Nat Genet. 2019;51:793-803.

59. Watson HJ, Yilmaz Z, Thornton LM, Hübel C, Coleman JRI, Gaspar HA, et al. Genomewide association study identifies eight risk loci and implicates metabo-psychiatric origins for anorexia nervosa. Nat Genet. 2019;51:1207-1214.

60. Ripke S, Walters JTR, O'Donovan MC, the Psychiatric Genomics Consortium SWG of, Others. Mapping genomic loci prioritises genes and implicates synaptic biology in schizophrenia. MedRxiv. 2020. 
medRxiv preprint doi: https://doi.org/10.1101/2021.02.15.21251736; this version posted February 19, 2021. The copyright holder for this preprint

(which was not certified by peer review) is the author/funder, who has granted medRxiv a license to display the preprint in perpetuity.

All rights reserved. No reuse allowed without permission.

61. Lee PH, Anttila V, Won H, Grünblatt E, Walitza S. Genome wide meta-analysis identifies genomic relationships, novel loci, and pleiotropic mechanisms across eight psychiatric disorders. 2019.

62. Lloyd-Jones LR, Zeng J, Sidorenko J, Yengo L, Moser G, Kemper KE, et al. Improved polygenic prediction by Bayesian multiple regression on summary statistics. Nat Commun. 2019;10:5086.

63. Uban KA, Horton MK, Jacobus J, Heyser C, Thompson WK, Tapert SF, et al. Biospecimens and the ABCD study: Rationale, methods of collection, measurement and early data. Dev Cogn Neurosci. 2018;32:97-106.

64. Das S, Forer L, Schönherr S, Sidore C, Locke AE, Kwong A, et al. Next-generation genotype imputation service and methods. Nat Genet. 2016;48:1284-1287. 